\title{
BMJ Open To what extent do education and physical work load factors explain occupational differences in disability retirement due to knee OA? A nationwide register-based study in Finland
}

Tea Kontio, ${ }^{1}$ Eira Viikari-Juntura, ${ }^{2}$ Svetlana Solovieva ${ }^{2}$

To cite: Kontio T, ViikariJuntura E, Solovieva S. To what extent do education and physical work load factors explain occupational differences in disability retirement due to knee $\mathrm{OA}$ ? A nationwide register-based study in Finland. BMJ Open 2018;8:e023057. doi:10.1136/ bmjopen-2018-023057

- Prepublication history and additional material for this paper are available online. To view these files, please visit the journal online (http://dx.doi org/10.1136/bmjopen-2018023057).

Received 19 March 2018 Revised 9 0ctober 2018 Accepted 22 October 2018
Check for updates

(C) Author(s) (or their employer(s)) 2018. Re-use permitted under CC BY-NC. No commercial re-use. See rights and permissions. Published by BMJ.

${ }^{1}$ Medical Faculty, University of Helsinki, Helsinki, Finland

${ }^{2}$ Finnish Institute of Occupational Health, Helsinki, Finland

Correspondence to

Dr Svetlana Solovieva;

svetlana.solovieva@ttl.fi

\section{ABSTRACT}

Objectives To examine the association of education and physical work load factors on the occupational differences in disability retirement due to knee osteoarthritis $(\mathrm{OA})$.

Design Longitudinal study.

Setting Linkage of several nationwide registers and a job exposure matrix in Finland.

Participants A total of 1135654 Finns aged 30-60 years in gainful employment were followed from 2005 to 2013 for full disability retirement due to knee $0 \mathrm{~A}$.

Primary and secondary outcome measures We calculated age-adjusted incidence rates and examined the association of occupation, education and physical work load factors with disability retirement using competing risk regression model. Disability retirement due to other causes than knee $0 \mathrm{~A}$, old-age retirement and death were treated as competing risk.

Results A total of 6117 persons had disability retirement due to knee $0 \mathrm{~A}$. Women had a higher age-adjusted incidence rate than men (72 vs 60 per 100000 personyears, respectively). In men, a very high risk of disability retirement was found among construction workers, electricians and plumbers (HR 16.6, $95 \% \mathrm{Cl} 12.5$ to 22.2), service workers (HR 12.7, $95 \% \mathrm{Cl} 9.2$ to 17.4) and in women among building caretakers, cleaners, assistant nurses and kitchen workers (HR 15.5, 95\% $\mathrm{Cl} 11.7$ to 20.6), as compared with professionals. The observed occupational differences were largely explained by educational level and noticeably mediated by physical work load factors in both genders.

Conclusion Our observational study suggests that the risk of disability retirement among manual workers is strongly attributed to the physically heavy work.

\section{INTRODUCTION}

Population ageing confronts most of the high-income countries with a rapid decline in the proportion of people participating in labour force. The proportion of people aged $>60$ years is predicted by 2050 to represent $37 \%$ of the population in Europe and
Strengths and limitations of this study

- This is one of the few population-based studies and among the largest on occupational differences in disability retirement due to knee osteoarthritis that includes both men and women and information on physical work load factors assessed by a job exposure matrix.

- We used longitudinal population-based register data with very good statistical power and without missing information or loss to follow-up.

- We applied a competing risk model to estimate the occupation-specific risk of disability retirement due to knee $0 \mathrm{~A}$

- We estimated the mediating effect of physical load factors on the association between the occupation and disability retirement due to knee $0 \mathrm{~A}$.

- Using register-based data, the residual confounding due to lifestyle factors that affect decisions regarding disability retirement cannot be ruled out.

$22 \%$ of the population worldwide. ${ }^{1}$ Prolongation of work careers and increasing participation in work are set as national goals in the Nordic countries as well as many other Western countries.

Osteoarthritis (OA) is the most common chronic joint disorder, rapidly increasing with ageing population. ${ }^{23}$ The knee joint is most often affected by OA, especially among women. ${ }^{2}$ The Global Burden of Disease Study 2015 ranked OA as the 13th (overall) and 8th (among those above 50 years of age) highest contributor to global disability. ${ }^{4}$ Although OA is traditionally considered as an age-related disorder, the earlier stage of the disease starts at an age when people are still working. ${ }^{5}$

Epidemiological studies provide consistent evidence linking occupational physical 
activities with $\mathrm{OA}$ of the knee..$^{5-7}$ On the other hand, knee OA was found to be associated with reduced work participation, loss of work productivity, work $\operatorname{loss}^{58-10}$ and withdrawal from the labour force due to work disability retirement as well as premature age-based retirement. ${ }^{11}$

Occupations may differ regarding possibilities for people with OA to perform job tasks. Earlier studies have reported a considerable occupational variation in all-cause disability retirement. ${ }^{12-14}$ Differences in work-related exposure levels between occupations are well recognised ${ }^{15}$; however, a review by Allebeck and Mastekaasa ${ }^{16}$ found only limited scientific evidence for the impact of physically demanding work on disability retirement. Education, as one of the indicators of socioeconomic status, has consistently been associated with disability retirement. ${ }^{17-19}$ People with low education are more likely working in manual occupations with physically demanding tasks. ${ }^{20}$ Previous studies ${ }^{14} 1621$ suggest that working conditions and health behaviours contribute to the socioeconomic differences in disability retirement, but the magnitudes of the effects have generally been moderate. Knowledge on occupational inequalities in cause-specific disability retirement is limited. A recent study observed a particularly high risk of disability retirement due to knee OA among women working in cleaning and men in metal work. ${ }^{22}$

The aim of this study was to identify occupations with a high risk of disability retirement due to knee OA in the Finnish population and to examine the impact of work-related factors on occupational differences in disability retirement. We expected that the effects of occupation on disability retirement are mediated through physical working conditions. Educational level, however, often predetermines the selection of occupation, and may therefore operate as a confounder for occupational differences in disability retirement.

\section{MATERIALS AND METHODS}

\section{Setting and data sources}

This was a population-based study, using register data from a $70 \%$ random sample of the Finnish population aged 18-70 years living in Finland on 31 December 2004 ( 2.5 million). Persons aged 30-60 years (as of December 2004), who were in gainful employment on 1 January 2005 , were eligible to the study. We excluded persons who did not have an occupational title or those who started to receive any retirement-related benefit (full disability retirement, partial or full old-age retirement, unemployment retirement) before 1 January 2005. Our cohort consisted of 1135654 persons (574617 men and 561037 women).

\section{National register of the Finnish Centre for Pensions}

Information on employee pensions, earning periods and unemployment related unsalaried periods was obtained from the register held by the Finnish Centre for Pensions. The register covers everyone who is a Finnish citizen or permanent resident of Finland. In Finland, people with a chronic illness, disability or injury that has been verified by a physician with a medical certificate and evaluated as causing considerable and long-lasting (about 1 year) decreased work ability are entitled to disability pension. ${ }^{23} 24$

If there is a possibility to restore the employee's work ability through rehabilitation or treatment, a temporary pension for a fixed period can be granted by the pension provider. Temporary disability pension can often be continued after the initial period; however, a decision regarding permanent disability pension is made within 2 years.

\section{Disability retirement due to knee $\mathrm{OA}$}

The register provides information on all disability retirement events with their primary and secondary diagnoses, which are classified according to The International Statistical Classification of Diseases and Related Health Problems, Tenth Revision (ICD-10, Finnish version of ICD-classification 1996). The outcome of this study was full-time disability retirement (either temporary or permanent) due to knee OA (M17) during the period from 1 January 2005 to 31 December 2013.

\section{Occupation}

Information on the persons' occupation held on the 31 December 2004 was obtained from the Finnish Longitudinal Employer-Employee Data (FLEED) of Statistics Finland. The FLEED provide information by region on, for example, the population's sociodemographic factors, living conditions, economic activity and employment. Around 40 nationwide administrative registers, annually updated, serve as the source of information. The database includes all permanent residents in the country on the last day of the year. The occupations were classified up to 4-digit level according to the Classification of Occupations 2001 by Statistics Finland, which is based on the International Standard Classification of Occupations (ISCO-88). For the analysis, the occupations were aggregated to the 2-digit level (see online supplementary table S1).

\section{Physical work load factors}

Heavy physical work (eg, involving lifting and carrying heavy loads, excavating, shovelling or hammering), kneeling or squatting at work (for at least 1 hour a day), manual handling of heavy loads (lifting, carrying or pushing items heavier than $20 \mathrm{~kg}$ at least 10 times every day), sitting at work (on average at least 5 hours per day) and standing or moving at work (on average at least 5 hours per day) were estimated with a gender-specific job exposure matrix (JEM) developed earlier in a large population survey. ${ }^{25}$ The JEM includes exposure information for $>401$ occupations, coded according to the Classification of Occupations 2001 by Statistics Finland.

\section{Education}

Information on the persons' education achieved by 31 December 2004 was obtained from FLEED of Statistics 
Finland. Education was categorised as 0) unknown, 1) primary, 2) secondary, 3) lower tertiary and 4) higher tertiary.

\section{Statistical analysis}

We calculated age-adjusted (age groups 30-39, 40-49, 50-59 and 60 or more years) incidence rates (per 100000 person-years) of disability retirement due to knee OA by occupational group and estimated $95 \%$ CIs using a Poisson distribution. Calculation of the CI for the incidence rate of a disease is typically done by computing the CI from a sample of observations drawn at random from a Poisson distribution. ${ }^{26}$ The persons were followed from 1 January 2005 until 31 December 2013 for the first occurrence of temporary or permanent full disability retirement due to knee OA.

Our primary aim was to examine, whether the effect of occupation on disability retirement due to knee OA is mediated by physical work load factors. As a secondary aim, we explored to which extent the association between occupation and disability retirement is affected by the level of education.

We assumed that education predetermines the selection of occupation, which in turn predetermines physical load factors at work, which may cause knee OA and result in disability retirement. We also assumed that education may be associated with disability retirement directly or indirectly via another pathway than that mentioned above (eg, lifestyle factors).

First, we explored the association between individual physical work load factors and disability retirement controlling for age. After this, we included all physical work load factors simultaneously into the age-adjusted model. Finally, we did further adjustment for education. The mediating effect of physical work load was tested after the association between occupation and disability retirement was controlled for education. For that, the contribution of education and physical work-related factors to the association between occupation and disability retirement was examined by consecutively including education (model 2) and physical work-related factors (model 3) into the age-adjusted model (model 1 ).

We used competing risk regression model (stcrreg, STATA V.14) to estimate HRs and their 95\% CI and to test for the association between occupation, physical work load factors, education and full disability retirement. We accounted for the effect on the outcome of the following competing risks: full disability retirement due to other causes than knee OA, old-age retirement and death. In analyses of occupational differences, the reference group consisted of professionals.

To estimate the contribution of the explanatory factors to the observed statistically significant associations, we calculated the percentage of attenuation of HR for all occupations (with professionals as reference) after adjustment, using the formula ${ }^{27}:\left(\mathrm{HR}_{\text {Model_i }}-\mathrm{HR}_{\text {Model_i+1 }}\right) /\left(\mathrm{HR}_{\text {Mod- }}\right.$ el_i ${ }^{-1)} \times 100 \%, \mathrm{i}=1,2$.
We also examined separately the contribution of each physical work load factor to the excess risk of disability retirement. For that we compared the HRs adjusted for age, education and physical work load factor in question with HRs adjusted for age and education.

The analyses were made separately for men and women.

\section{Patient and public involvement}

No patients or public were involved in the study and there are no plans to disseminate the results of the research to these parties.

\section{RESULTS}

\section{Description of sample}

In total, 1135654 persons (49.4\% women) met the inclusion criteria. At baseline, women were slightly older ( $45.3 \pm 8.4$ vs $44.6 \pm 8.3$ years), had more frequently attained tertiary education ( $30.5 \%$ vs $16.7 \%)$ and were more often employed in the public sector $(46.2 \%$ vs $17.1 \%)$ than men. Men most likely worked in manual occupations and women in lower-level non-manual occupations (table 1).

A notable gender difference in education was observed within occupational groups. In particular, female environmental officers and nurses, office clerks, agricultural and fishery workers, professional drivers as well as construction workers, electricians and plumbers were more educated than males in the corresponding occupations. In contrast, male physical and engineering science technicians, customer services clerks, service workers and metal and machinery workers had attained higher education as compared with females in the corresponding occupations (table 1).

\section{Incidence rate of full disability retirement due to knee $\mathrm{OA}$}

From 1 January 2005 until 31 December 2013, a total of 6117 persons (2836 men and 3281 women) had full disability retirement due to knee OA. Overall age-adjusted incidence rate of disability retirement was 60 and 72 per 100000 person-years for men and women, respectively (table 2). Among men, construction workers, electricians and plumbers showed the highest incidence rates, while among women, building caretakers, cleaners, assistant nurses and kitchen workers had the highest incidence rate. Other occupations with higher incidence rate than the population average included agricultural and fishery workers (both genders), metal and machinery workers (men), wood and metal processing workers (both genders), unskilled transport, construction and manufacturing workers (women), as well as service workers (women).

\section{Physical work-related factors and disability retirement}

The distribution of physical work load factors by occupational group and by education are presented in online supplementary table S2 and S3, respectively. In the age-adjusted models, all physical load factors 
Table 1 Baseline characteristics of those aged 30-60 years $(A)$ men $(n=574617)$ and $(B)$ women $(n=561037)$

Education (\%)

Sector of employment (\%)

ISCO-88 Lower Higher code Occupational group $\quad \% \quad$ Age Primary Secondary tertiary tertiary Private Public employed

(A) Men

Upper-level non-manual occupations

\begin{tabular}{|c|c|c|c|c|c|c|c|c|c|c|}
\hline $11,12,13$ & Managers & 5.8 & 46.3 & 6.7 & 17.2 & 26.4 & 49.7 & 79.7 & 19.0 & 1.4 \\
\hline $21,22,24$ & Professionals & 13.5 & 43.9 & 4.1 & 15.9 & 18.5 & 61.5 & 66.6 & 26.2 & 7.2 \\
\hline \multirow[t]{2}{*}{23} & Teaching professionals & 4.0 & 45.2 & 3.6 & 15.2 & 22.3 & 58.9 & 16.8 & 79.0 & 4.2 \\
\hline & \multicolumn{10}{|c|}{ Lower-level non-manual occupations } \\
\hline 31 & $\begin{array}{l}\text { Physical and engineering } \\
\text { science technicians }\end{array}$ & 8.3 & 44.4 & 8.3 & 26.4 & 42.3 & 23.0 & 76.4 & 15.3 & 8.3 \\
\hline 32 & $\begin{array}{l}\text { Environmental officers and } \\
\text { nurses }\end{array}$ & 1.0 & 43.4 & 5.2 & 17.2 & 59.1 & 18.5 & 39.1 & 48.3 & 12.7 \\
\hline 33,34 & $\begin{array}{l}\text { Finance and sales } \\
\text { associate professionals and } \\
\text { administrative secretaries }\end{array}$ & 8.7 & 44.6 & 16.1 & 33.2 & 36.3 & 14.4 & 59.2 & 15.4 & 25.5 \\
\hline 41 & Office clerks & 3.2 & 44.7 & 29.3 & 41.8 & 21.6 & 7.3 & 76.0 & 21.4 & 2.6 \\
\hline 42 & Customer services clerks & 0.3 & 41.7 & 13.3 & 36.2 & 40.6 & 9.9 & 83.9 & 7.3 & 8.8 \\
\hline 51 & Service workers & 3.9 & 42.4 & 19.2 & 64.9 & 13.1 & 2.8 & 41.7 & 40.2 & 18.1 \\
\hline \multirow[t]{2}{*}{52} & Shop workers & 2.3 & 42.8 & 30.4 & 45.1 & 22.0 & 2.5 & 93.0 & 0.2 & 6.9 \\
\hline & \multicolumn{10}{|l|}{ Manual occupations } \\
\hline 61,92 & $\begin{array}{l}\text { Agricultural and fishery } \\
\text { workers }\end{array}$ & 6.0 & 46.8 & 32.7 & 56.0 & 8.6 & 2.7 & 8.4 & 7.3 & 84.4 \\
\hline 71 & $\begin{array}{l}\text { Construction workers, } \\
\text { electricians and plumbers }\end{array}$ & 8.3 & 44.7 & 31.19 & 64.0 & 3.8 & 1.0 & 69.7 & 6.3 & 24.1 \\
\hline 72 & $\begin{array}{l}\text { Metal and machinery } \\
\text { workers }\end{array}$ & 10.8 & 45.0 & 17.1 & 77.2 & 4.4 & 1.3 & 79.9 & 6.7 & 13.4 \\
\hline 73,74 & Craft workers & 2.0 & 44.7 & 26.2 & 60.8 & 10.6 & 2.4 & 73.7 & 3.5 & 22.8 \\
\hline 81 & $\begin{array}{l}\text { Chemical, wood and metal } \\
\text { processing workers }\end{array}$ & 3.3 & 44.6 & 30.8 & 62.7 & 5.3 & 1.2 & 94.1 & 3.6 & 2.3 \\
\hline 82 & $\begin{array}{l}\text { Machine operators and } \\
\text { assemblers }\end{array}$ & 4.6 & 43.4 & 32.8 & 59.8 & 6.0 & 1.4 & 94.7 & 0.5 & 4.8 \\
\hline 83 & Professional drivers & 8.0 & 45.1 & 43.4 & 51.8 & 4.1 & 0.7 & 69.9 & 7.6 & 22.6 \\
\hline 91 & $\begin{array}{l}\text { Building caretakers, } \\
\text { cleaners, assistant nurses } \\
\text { and kitchen workers }\end{array}$ & 2.9 & 45.2 & 35.0 & 57.4 & 5.8 & 1.8 & 57.4 & 38.9 & 3.7 \\
\hline 93 & $\begin{array}{l}\text { Unskilled transport, } \\
\text { construction and } \\
\text { manufacturing workers }\end{array}$ & 3.2 & 44.1 & 39.0 & 53.8 & 6.2 & 1.0 & 88.9 & 10.0 & 1.1 \\
\hline
\end{tabular}

(B) Women

\begin{tabular}{|c|c|c|c|c|c|c|c|c|c|c|}
\hline & Upper-level non-manual occ & patior & & & & & & & & \\
\hline $11,12,13$ & Managers & 2.8 & 46.2 & 3.9 & 15.9 & 42.1 & 38.1 & 56.9 & 42.2 & 0.9 \\
\hline $21,22,24$ & Professionals & 10.2 & 44.2 & 3.1 & 12.6 & 31.1 & 53.2 & 41.4 & 51.7 & 6.9 \\
\hline \multirow[t]{2}{*}{23} & Teaching professionals & 8.3 & 44.0 & 1.6 & 8.1 & 36.2 & 54.1 & 10.3 & 87.1 & 2.6 \\
\hline & \multicolumn{10}{|c|}{ Lower-level non-manual occupations } \\
\hline 31 & $\begin{array}{l}\text { Physical and engineering } \\
\text { science technicians }\end{array}$ & 1.9 & 43.4 & 11.1 & 37.6 & 31.0 & 20.3 & 70.3 & 24.5 & 5.3 \\
\hline 32 & $\begin{array}{l}\text { Environmental officers and } \\
\text { nurses }\end{array}$ & 7.6 & 44.0 & 1.5 & 7.9 & 77.0 & 13.6 & 22.3 & 73.5 & 4.2 \\
\hline
\end{tabular}

Continued 
Table 1 Continued

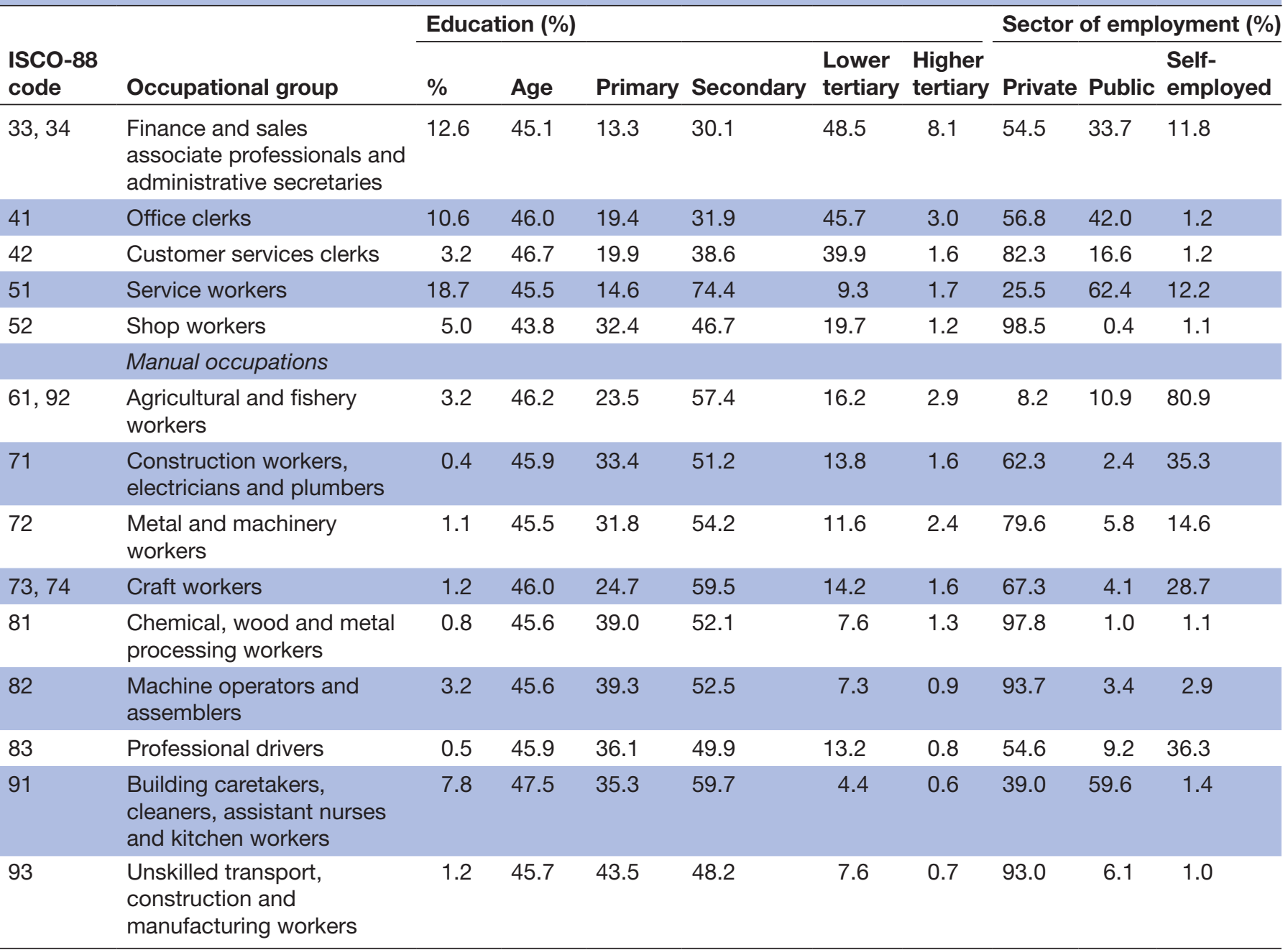

ISCO, International Standard Classification of Occupations.

were statistically significantly associated with disability retirement due to knee $\mathrm{OA}$ in both genders (table 3). Four out of five physical load factors increased the risk of disability retirement, whereas sitting reduced the risk. With all physical load factors in the model, the associations of heavy lifting with disability retirement (both genders) lost their statistical significance. Further adjustment for education attenuated the risk estimates, especially among women.

\section{Risk of disability retirement due to knee $\mathrm{OA}$ by occupation}

Among men, the age-adjusted risk of disability retirement due to knee OA was increased in all occupations except managers and teaching professionals as compared with the professionals (table 4). Construction workers, electricians and plumbers had the highest (OR 16.6, 95\% CI 12.5. to 22.2), and service workers, as well as unskilled transport, construction and manufacturing workers had the second highest risk. Among women, the age-adjusted risk of disability retirement was increased in all occupations as compared with the professionals, building caretakers, cleaners, assistant nurses and kitchen workers having the highest risk (HR $15.5,95 \%$ CI 11.7 to 20.6 ).

In both genders, adjustment for education considerably attenuated the occupational differences in disability retirement due to knee OA (table 4). Among men, the reduction in the risk varied between $52.7 \%$ (physical and engineering science technicians) and $75.2 \%$ (shop workers). Among women, the reduction in risk of disability retirement was highest for customer services clerks and second highest for physical and engineering science technicians. However, adjustment for education somewhat increased the risk for disability retirement for female teaching professionals, suggesting negative confounding.

\section{Influence of physical work load factors on occupational} differences in disability retirement due to knee $0 \mathrm{~A}$

The combined contribution of physical work load factors to the risk of disability retirement due to knee OA varied between $14.2 \%$ and $85.2 \%$ among men and $16.7 \%$ and $120.7 \%$ among women (table 4). Among men, the largest influence of the physical work load 
Table 2 Age-adjusted incidence rate (IR per 100000 person-years) and $95 \% \mathrm{Cl}$ of full-time disability retirement due to knee osteoarthritis during 2005-2013 among men and women by occupational group

\begin{tabular}{lrrrrr}
\hline & Men & & Women & \\
\cline { 2 - 3 } Occupational group & IR & $\mathbf{9 5 \%} \mathbf{C l}$ & IR & $\mathbf{9 5 \%} \mathbf{C l}$ \\
\hline Managers & 10 & 6 to 21 & 20 & 10 to 46 \\
\hline Professionals & 8 & 5 to 13 & 10 & 6 to 18 \\
\hline Teaching professionals & 12 & 6 to 23 & 16 & 10 to 25 \\
\hline $\begin{array}{l}\text { Physical and engineering science technicians } \\
\text { Environmental officers and nurses }\end{array}$ & 34 & 25 to 50 & 20 & 10 to 45 \\
\hline $\begin{array}{l}\text { Finance and sales associate professionals and administrative } \\
\text { secretaries }\end{array}$ & 22 & 72 & 23 to 75 & 33 & 23 to 50 \\
\hline Office clerks & 56 & 37 to 37 & 32 & 22 to 42 \\
\hline Customer services clerks & 21 & 5 to 108 & 25 & 13 to 50 \\
\hline Service workers & 81 & 59 to 117 & 118 & 104 to 134 \\
\hline Shop workers & 30 & 15 to 69 & 86 & 66 to 117 \\
\hline Agricultural and fishery workers & 92 & 72 to 120 & 199 & 157 to 257 \\
\hline Construction workers, electricians and plumbers & 142 & 120 to 170 & 87 & 34 to 247 \\
\hline Metal and machinery workers & 102 & 87 to 122 & 56 & 24 to 144 \\
\hline Craft workers & 66 & 40 to 118 & 78 & 46 to 141 \\
\hline Chemical, wood and metal processing workers & 98 & 71 to 140 & 132 & 79 to 235 \\
\hline Machine operators and assemblers & 64 & 46 to 90 & 101 & 75 to 142 \\
\hline Professional drivers & 70 & 55 to 91 & 141 & 77 to 261 \\
\hline Building caretakers, cleaners, assistant nurses and kitchen workers & 112 & 82 to 157 & 246 & 216 to 282 \\
\hline Unskilled transport, construction and manufacturing workers & 104 & 76 to 148 & 133 & 84 to 230 \\
\hline All & 60 & 56 to 65 & 72 & 67 to 77 \\
\hline
\end{tabular}

factors on occupational differences in disability retirement was found among construction workers, electricians and plumbers. Agricultural and fishery workers had the second highest contribution of work load factors to the risk $(77.7 \%)$. With physical load factors in the model the risk of disability retirement lost its statistical significance for shop workers as well as agricultural and fishery workers and remained statistically significant for most of the other o ccupations.

Table 3 Associations between physical work load factors and disability retirement due to knee osteoarthritis among men and women

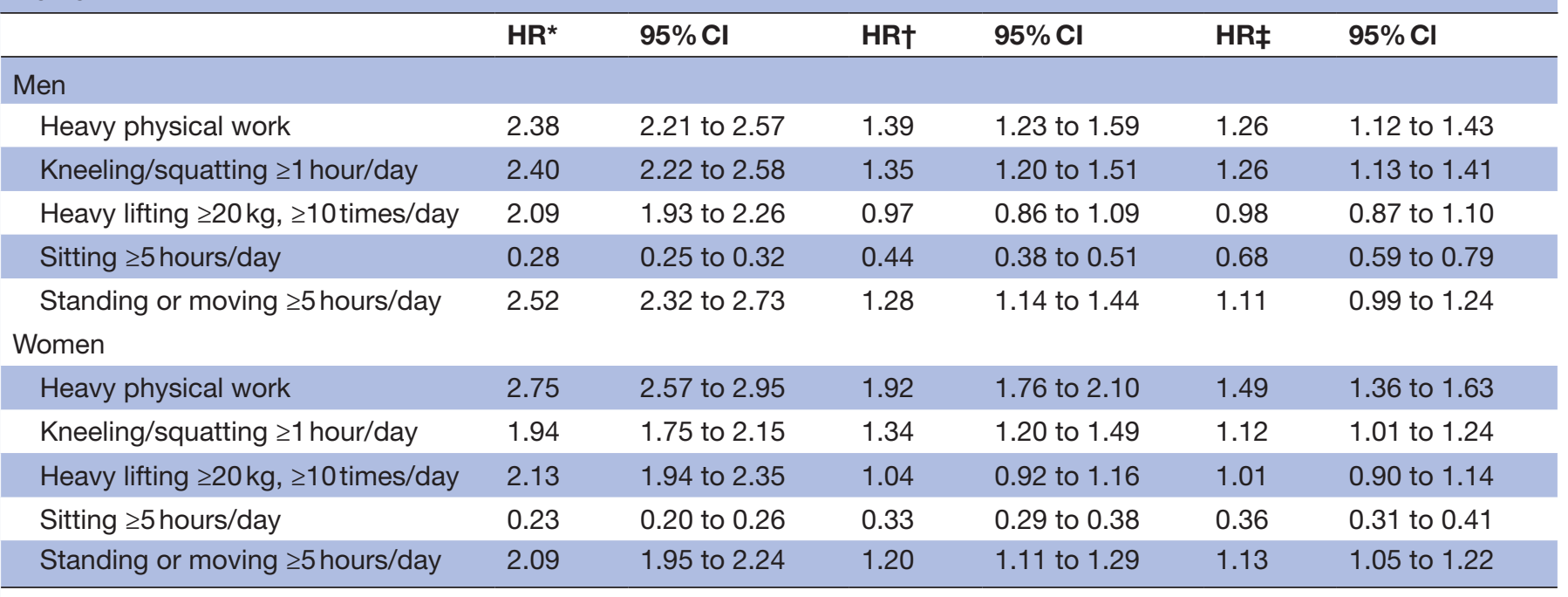

${ }^{*}$ Adjusted for age.

†Adjusted for age and mutually (for all variables in the table).

$\ddagger$ Adjusted for age, education and mutually. 


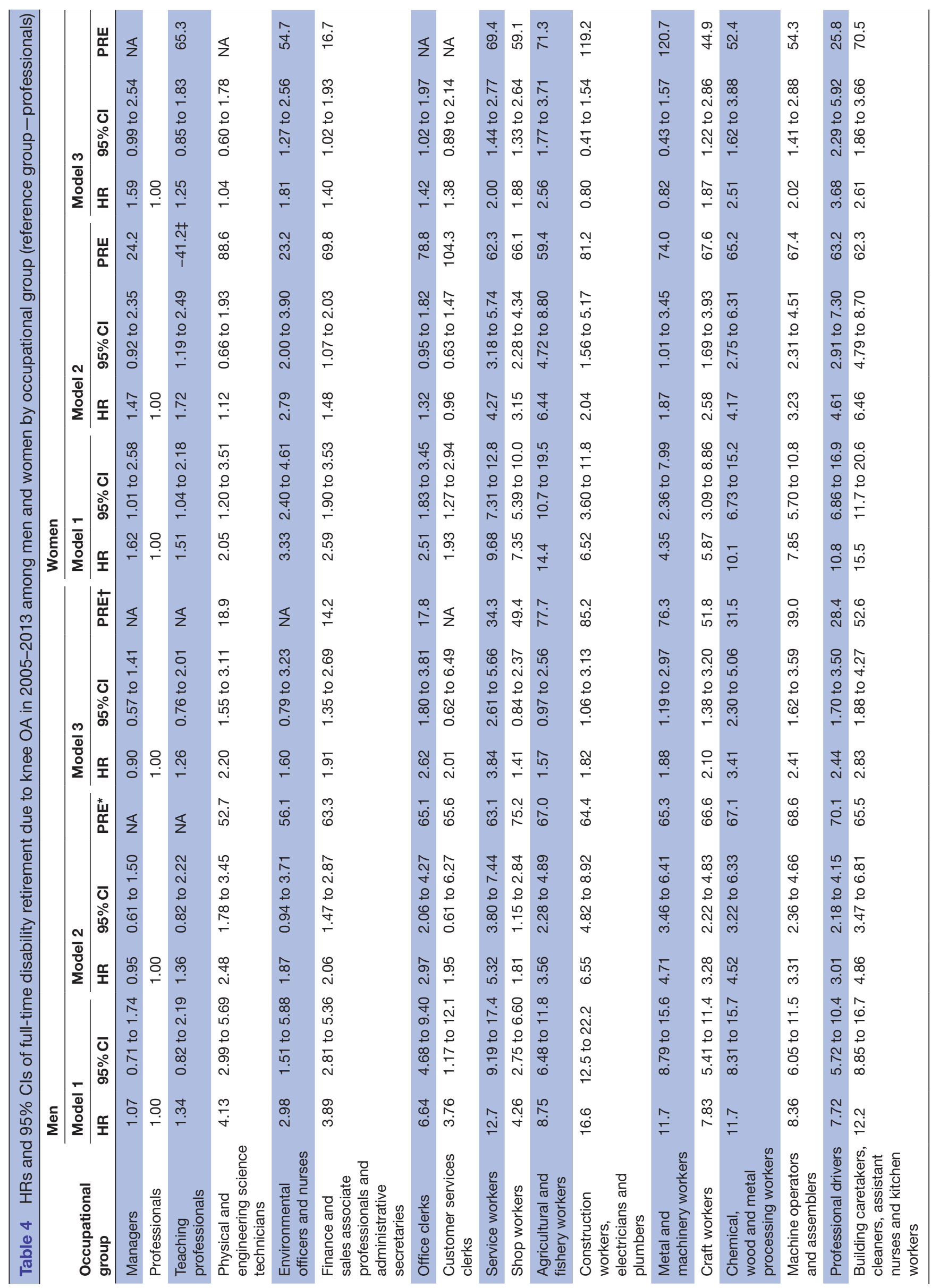


The physical work load factors completely mediated the effect on disability retirement due to knee OA among female construction workers, electricians and plumbers as well as metal and machinery workers and teaching professionals (table 4). In general, the contribution of physical work load factors to occupational differences in disability retirement was larger among women than among men in manual occupations. Among female managers and office clerks, adjustment for physical work load factors increased the risk of disability retirement, suggesting that occupational factors do not play a role in the increased risk for these occupations.

The physical load that explained the highest contribution to the excess risk among men was kneeling and squatting (table 5). The proportion of the risk explained was especially high for the construction workers, electricians and plumbers $(84.3 \%)$, metal and machinery workers $(75.5 \%)$ and agricultural and fishery workers $(75.4 \%)$. However, among women heavy physical work contributed most to the excess risk within construction workers, electricians and plumbers $(96.2 \%)$, unskilled transport, construction and manufacturing workers $(70.2 \%)$, metal and machinery workers $(80.5 \%)$ and agricultural and fishery workers $(66.5 \%)$.

\section{DISCUSSION}

This is one of the few population-based studies and among the largest on occupational differences in disability retirement due to knee OA that includes both men and women and information on physical work load factors assessed by a job exposure matrix. We observed considerable occupational differences in the 9-year incidence rate of disability retirement due to knee OA in both genders. The overall incidence rate was significantly higher in women than men, with the largest gender difference among building caretakers, cleaners, assistant nurses and kitchen workers as well as agricultural and fishery workers. The observed occupational differences in disability retirement were considerably attenuated after controlling for education. Physical work load factors noticeably mediated the effect of occupation on disability retirement in both genders.

\section{Comparison with previous studies}

The majority of previous studies on the association between occupation and knee OA have used either case-control or cross-sectional design, have been based on a selected set of occupations or examined the association among men only. We estimated the risk of disability retirement due to knee OA across a wide range of occupations (including all non-manual and manual occupations held by Finns in 2005). Our results on an excessive risk of disability retirement among male construction workers, electricians and plumbers as well as metal and machinery workers; female building caretakers, cleaners, assistant nurses and kitchen workers as well as agricultural and fishery workers and chemical, 
Table 5 The contribution of separate physical work load factors on the occupational differences in disability retirement due to knee OA among men and women (reference group-professionals)

\begin{tabular}{|c|c|c|c|c|c|c|c|c|c|c|}
\hline \multirow[b]{3}{*}{ Occupational group } & \multicolumn{10}{|c|}{ Proportion (\%) of risk of disability retirement due to knee OA explained ${ }^{*}$} \\
\hline & \multicolumn{5}{|l|}{ Men } & \multicolumn{5}{|l|}{ Women } \\
\hline & HPW & $\mathbf{K}$ & HL & Sit & Stand & HPW & $\mathbf{K}$ & HL & Sit & Stand \\
\hline Managers & NA & NA & NA & NA & NA & NA & NA & NA & NA & NA \\
\hline \multicolumn{11}{|l|}{ Professionals } \\
\hline Teaching professionals & NA & NA & NA & NA & NA & $-6.93 \dagger$ & 11.1 & 0.0 & 66.7 & 18.1 \\
\hline $\begin{array}{l}\text { Physical and engineering science } \\
\text { technicians }\end{array}$ & 9.5 & 16.9 & 10.8 & 20.3 & 4.1 & NA & NA & NA & NA & NA \\
\hline Environmental officers and nurses & NA & NA & NA & NA & NA & 39.7 & 10.1 & 4.5 & 34.1 & 10.6 \\
\hline $\begin{array}{l}\text { Finance and sales associate professionals } \\
\text { and administrative secretaries }\end{array}$ & 10.4 & 13.2 & 6.6 & 12.3 & 3.8 & 14.6 & 6.3 & 2.1 & 4.2 & -6.3 \\
\hline Office clerks & 20.8 & 10.7 & 8.1 & 13.7 & 2.5 & NA & NA & NA & NA & NA \\
\hline Customer services clerks & 0.0 & -2.1 & 2.1 & -11.6 & 0.0 & NA & NA & NA & NA & NA \\
\hline Service workers & 23.6 & 27.5 & 10.4 & 24.5 & 5.6 & 44.6 & 21.1 & 2.8 & 35.2 & 15.3 \\
\hline Shop workers & 34.6 & 44.4 & 37.0 & 53.1 & 13.6 & 35.8 & 11.6 & 3.3 & 30.7 & 22.8 \\
\hline Agricultural and fishery workers & 53.5 & 75.4 & 44.5 & 34.8 & 10.5 & 66.5 & 24.8 & 8.8 & 37.9 & -3.9 \\
\hline $\begin{array}{l}\text { Construction workers, electricians and } \\
\text { plumbers }\end{array}$ & 47.4 & 84.3 & 32.6 & 31.0 & 8.8 & 96.2 & 21.2 & -53.8 & 10.6 & -72.1 \\
\hline Metal and machinery workers & 30.7 & 75.5 & 18.1 & 30.7 & 8.1 & 80.5 & 54.0 & 9.2 & 49.4 & 28.7 \\
\hline Craft workers & 27.2 & 46.9 & 18.0 & 24.6 & 4.4 & 35.4 & 8.9 & 2.5 & 22.2 & 0.0 \\
\hline $\begin{array}{l}\text { Chemical, wood and metal processing } \\
\text { workers }\end{array}$ & 24.7 & 28.4 & 21.9 & 22.7 & 6.0 & 50.2 & 4.4 & 3.5 & 19.9 & 11.0 \\
\hline Machine operators and assemblers & 27.3 & 35.9 & 24.2 & 26.0 & 6.5 & 54.3 & 2.2 & 2.7 & 12.6 & 11.7 \\
\hline Professional drivers & 32.8 & 18.9 & 28.4 & 17.4 & 0.5 & 47.9 & 6.1 & 6.9 & -2.5 & -0.6 \\
\hline $\begin{array}{l}\text { Building caretakers, cleaners, assistant } \\
\text { nurses and kitchen workers }\end{array}$ & 29.8 & 46.6 & 13.0 & 29.3 & 6.2 & 48.0 & 19.0 & 2.7 & 37.2 & 14.1 \\
\hline $\begin{array}{l}\text { Unskilled transport, construction and } \\
\text { manufacturing workers }\end{array}$ & 38.2 & 46.5 & 29.9 & 27.9 & 7.3 & 70.2 & 13.9 & 6.5 & 29.4 & 19.4 \\
\hline
\end{tabular}

${ }^{*}$ The percentage of attenuation of $\mathrm{HR}$ (with professionals as reference) after adjustment: $\left(\mathrm{HR}_{\text {Model } 3}-\mathrm{HR}_{\text {Model } 2}\right) /\left(\mathrm{HR} \mathrm{M}_{\text {Model } 2}-1\right) \times 100 \%$, model 2 adjusted for age and education, model 3 adjusted for age, education and physical work load factor.

†Negative value indicates an increase in HR after adjustment for the physical work load factor in question.

HL, heavy lifting; HPW, heavy physical work; K, kneeling or squatting; NA, not applicable; Sit, sitting; Stand, standing or moving.

wood and metal processing workers of both genders are in line with the previous studies reporting an association of occupation with OA. ${ }^{22} 28-30$

There is growing evidence on the detrimental effect of significant and recurrent squatting, bending, kneeling and loading of the knee on the development of knee $\mathrm{OA}^{7}$ It has been suggested that social and occupational differences in disability retirement could be due to unfavourable physical working conditions that vary across occupations. Indeed, it has been estimated that about $5 \%$ of knee OA might result from occupations involving repetitive knee use. ${ }^{31}{ }^{32}$ Our findings suggest that at least $50 \%$ of disability retirement due to knee OA among individuals in most manual occupations could be attributed to physical work load factors. In fact, our results suggest that the excess risk of disability retirement among male shop workers as well as agricultural and fishery workers, and female construction workers, electricians and plumbers could be eliminated if the physical work load factors would be at the level of those among professionals. The contribution of physical load factors to disability risk among professional drivers was modest.

It is well documented that women have higher incidence rates of knee OA than men, especially after the age of 50 years. ${ }^{7}$ However, gender-specific occupational differences in OA are largely unknown. We observed a clear gender difference in the incidence rate of disability retirement due to knee OA among Finns aged 30-60 years. In particular, female agricultural and fishery workers and women working as building caretakers, cleaners, assistant nurses and kitchen workers had a twofold incidence rate of disability retirement as compared with men in those occupations.

The level of education has been well documented to be one of the strongest determinants of social inequality 
in health and disability retirement in particular. ${ }^{17-19}$ Previous studies have suggested that occupational class and working conditions are the major contributors to these associations. ${ }^{14161721}$ In our study, even after taking into account occupational differences in education and physical work load, the increased risk of disability retirement due to knee OA remained in most of the occupations. The remained risk of disability retirement was more than threefold among male service workers and male chemical, wood and metal processing workers (particularly, papermaking plant operators) and female professional drivers as compared with professionals. The findings suggest that these occupations may involve clustering of other risk factors (eg, obesity, smoking, psychosocial work-related factors) for disability due to knee OA that were not examined in our study. Indeed, a higher prevalence of obesity and smoking among fire-fighters, police workers ${ }^{33} 34$ as well as professional drivers than in the general population ${ }^{35} 36$ has been reported. However, the remained elevated risk of disability retirement for some occupations may still be due to physical load factors that were not captured by the JEM. Despite assessment of the physical work load factors by a gender-specific JEM, there may have been a non-differential misclassification of the exposures, particularly in occupations with larger within-occupation differences in the physical work load factors.

\section{Strengths and limitations}

The strength of the current study is that a large nationally representative sample of the Finnish working population was followed over a relatively long period of time. Information on physical work exposures for each occupation, classified based on the ISCO, was obtained from a gender-specific job exposure matrix and therefore the observed associations were not affected by recall bias. Furthermore, there was no selection and attrition bias, since the study was solely based on register data. There is strong epidemiological evidence suggesting an increased risk of disability retirement, earlier old-age retirement and mortality among workers with physically demanding work. ${ }^{37-40}$ To minimise an overestimation of HRs and to control for the potential effect of competing risks on disability retirement due to knee $\mathrm{OA}$, we conducted a competing risk analysis.

A major limitation of register-based studies, in general, is that they typically provide only a limited number of background characteristics of the participants and other potential confounders. Economic incentives may affect the propensity of persons to apply for disability pension. Those with higher socioeconomic status may want to stay at work, as their loss in income will be larger in absolute terms. On the other hand, those with lower socioeconomic status may also want to stay at work, as their income from disability pension may not be sufficient for their basic needs. However, persons in upper non-manual jobs may be able to stay at work despite knee problems, while for persons in manual occupations, working conditions may limit their work participation. Therefore, residual confounding due to lifestyle factors or other factors that affect decisions regarding disability retirement cannot be ruled out.

In conclusion, while there is sufficient evidence for occupation as a risk factor for knee OA among men, studies on occupational differences in knee OA and its consequences among women are scarce. The recent study provides comprehensive information on occupational differences in disability retirement due to knee OA in both genders and across a broad range of occupations. We observed an exceptionally high risk of disability retirement among male construction workers, electricians and plumbers, service workers, unskilled transport, construction and manufacturing workers as well as female building caretakers, cleaners, assistant nurses and kitchen workers. Our observational study suggests that the risk of disability retirement among manual workers is strongly attributed to the physically heavy work. Prevention measures should focus on the reduction of physically heavy tasks, kneeling or squatting activities and lifting and carrying of loads. More intervention studies on the effectiveness of aids and working methods for reducing knee straining activities are needed.

Contributors EV-J obtained the data. All authors were involved in study conception and design, interpretation of results. SS conducted the statistical analyses. TK wrote the first drafts of the article. All authors discussed the drafts, revised them critically and prepared the final version to be submitted for publication. SS has full access to all data in the study and takes responsibility of the integrity of the data and the accuracy of the data analysis.

Funding This work was supported by NordForsk grant number 76659 (SS), the Finnish Work Environment Fund grant number 115105 (SS) and by the Academy of Finland grant number 267589 (EV-J).

Competing interests None declared.

Patient consent Not required.

Ethics approval The researchers used fully anonymous register data for which ethics committee approval is not needed according to Finnish legislation. Statistics Finland linked its data to those of the Social Insurance Institution of Finland and the Finnish Centre for Pensions, after which the data were anonymised and stored by Statistics Finland. The researchers analysed the anonymous data using a remote access system. All output extracted from the system was approved by Statistics Finland to ensure compliance with data protection regulations. The data can only be accessed by individual researchers who have obtained permission from each of the administrative sources providing the data.

Provenance and peer review Not commissioned; externally peer reviewed.

Data sharing statement Due to data protection regulations of the administrative sources providing the register data, the authors do not have the permission to share the data. Permissions to use the register data can be applied from the Social Insurance Institution of Finland (http://www.kela.fi/web/en/research-data-requests), the Finnish Centre for Pensions (http://www.etk.fi/en/statistics-2/statistics/ producer-of-statistics/) and Statistics Finland (http://www.stat.fi/meta/tietosuoja/ kayttolupa_en.html).

Open access This is an open access article distributed in accordance with the Creative Commons Attribution Non Commercial (CC BY-NC 4.0) license, which permits others to distribute, remix, adapt, build upon this work non-commercially, and license their derivative works on different terms, provided the original work is properly cited, appropriate credit is given, any changes made indicated, and the use is non-commercial. See: http:// creativecommons.org/licenses/by-nc/4.0/. 


\section{REFERENCES}

1. Chatterji S, Byles J, Cutler D, et al. Health, functioning, and disability in older adults--present status and future implications. Lancet 2015;385:563-75.

2. Martel-Pelletier J, Barr AJ, Cicuttini FM, et al. Osteoarthritis. Nat Rev Dis Primers 2016;2:16072.

3. Xie F, Kovic B, Jin X, et al. Economic and humanistic burden of osteoarthritis: a systematic review of large sample studies. Pharmacoeconomics 2016;34:1087-100.

4. GBD 2015 DALYs and HALE Collaborators. Global, regional, and national disability-adjusted life-years (DALYs) for 315 diseases and injuries and healthy life expectancy (HALE), 1990-2015: a systematic analysis for the Global Burden of Disease Study 2015. Lancet 2016;388:1603-58.

5. Palmer KT, Goodson N. Ageing, musculoskeletal health and work. Best Pract Res Clin Rheumatol 2015;29:391-404.

6. Palmer KT. Occupational activities and osteoarthritis of the knee. $\mathrm{Br}$ Med Bull 2012;102:147-70.

7. Dulay GS, Cooper C, Dennison EM. Knee pain, knee injury, knee osteoarthritis \& work. Best Pract Res Clin Rheumatol 2015;29:454-61.

8. Bieleman HJ, Bierma-Zeinstra SM, Oosterveld FG, et al. The effect of osteoarthritis of the hip or knee on work participation. J Rheumatol 2011;38:1835-43.

9. Agaliotis M, Mackey MG, Jan S, et al. Burden of reduced work productivity among people with chronic knee pain: a systematic review. Occup Environ Med 2014;71:651-9.

10. Sharif B, Garner R, Sanmartin C, et al. Risk of work loss due to illness or disability in patients with osteoarthritis: a population-based cohort study. Rheumatology 2016;55:861-8.

11. Muchmore L, Lynch WD, Gardner HH, Williamson T, et al. Prevalence of arthritis and associated joint disorders in an employed population and the associated healthcare, sick leave, disability, and workers' compensation benefits cost and productivity loss of employers. $J$ Occup Environ Med 2003;45:369-78.

12. Hannerz HTF, Spangenberg S, Albertsen K. Industrial differences in disability retirement rates in Denmark, 1996-2000. Int J Occup Med Environ Health 2004;14:465-71.

13. Stattin M, Järvholm B. Occupation, work environment, and disability pension: a prospective study of construction workers. Scand J Public Health 2005;33:84-90.

14. Haukenes I, Mykletun A, Knudsen AK, et al. Disability pension by occupational class--the impact of work-related factors: the Hordaland Health Study Cohort. BMC Public Health 2011;11:406.

15. Niedhammer I, Chastang JF, David S, et al. The contribution of occupational factors to social inequalities in health: findings from the national French SUMER survey. Soc Sci Med 2008;67:1870-81.

16. Allebeck P, Mastekaasa A. Swedish Council on Technology Assessment in Health Care (SBU). Chapter 5. Risk factors for sick leave - general studies. Scand J Public Health Suppl 2004;63:49-108.

17. Bruusgaard D, Smeby L, Claussen B. Education and disability pension: a stronger association than previously found. Scand $J$ Public Health 2010;38:686-90.

18. Leinonen T, Martikainen P, Lahelma E. Interrelationships between education, occupational social class, and income as determinants of disability retirement. Scand J Public Health 2012;40:157-66.

19. Nilsen SM, Ernstsen L, Krokstad S, et al. Educational inequalities in disability pensioning - the impact of illness and occupational, psychosocial, and behavioural factors: the Nord-Trøndelag Health Study (HUNT). Scand J Public Health 2012;40:133-41.
20. Warren JR, Hoonakker P, Carayon P, et al. Job characteristics as mediators in SES-health relationships. Soc Sci Med 2004;59:1367-78.

21. Falkstedt D, Backhans $M$, Lundin A, et al. Do working conditions explain the increased risks of disability pension among men and women with low education? A follow-up of Swedish cohorts. Scand J Work Environ Health 2014;40:483-92

22. Hubertsson J, Turkiewicz A, Petersson IF, et al. Understanding occupation, sick leave, and disability pension due to knee and hip osteoarthritis from a sex perspective. Arthritis Care Res 2017;69:226-33.

23. Prinz C. Disability pensions in Finland. European disability pension policies. Vienna: Ashgate, 2003:165-96.

24. Laaksonen M, Gould R. Return to work after temporary disability pension in Finland. J Occup Rehabil 2015;25:471-80.

25. Solovieva S, Pehkonen I, Kausto J, et al. Development and validation of a job exposure matrix for physical risk factors in low back pain. PLoS One 2012;7:e48680.

26. Rothman KJ GS. Modern epidemiology. 2nd edn. Philadelphia: Lippincott-Raven, 1998.

27. Hafeman DM. "Proportion explained": a causal interpretation for standard measures of indirect effect? Am J Epidemiol 2009;170:1443-8.

28. Rossignol M, Leclerc A, Hilliquin $P$, et al. Primary osteoarthritis and occupations: a national cross sectional survey of 10412 symptomatic patients. Occup Environ Med 2003;60:882-6.

29. Rossignol M. Primary osteoarthritis and occupation in the Quebec national health and social survey. Occup Environ Med 2004;61:729-35.

30. Arndt V, Rothenbacher D, Daniel U, et al. Construction work and risk of occupational disability: a ten year follow up of 14,474 male workers. Occup Environ Med 2005;62:559-66.

31. Vignon E, Valat JP, Rossignol M, et al. Osteoarthritis of the knee and hip and activity: a systematic international review and synthesis (OASIS). Joint Bone Spine 2006;73:442-55.

32. Coggon D, Croft P, Kellingray S, et al. Occupational physical activities and osteoarthritis of the knee. Arthritis Rheum 2000;43:1443-9.

33. Plat MJ, Frings-Dresen MH, Sluiter JK. A systematic review of job-specific workers' health surveillance activities for fire-fighting, ambulance, police and military personnel. Int Arch Occup Environ Health 2011;84:839-57.

34. Da Silva FC, Hernandez SS, Gonçalves E, et al. Anthropometric indicators of obesity in policemen: a systematic review of observational studies. Int J Occup Med Environ Health 2014;27:891-901.

35. Jain NB, Hart JE, Smith TJ, et al. Smoking behavior in trucking industry workers. Am J Ind Med 2006;49:1013-20.

36. Rosso GL, Perotto M, Feola M, et al. Investigating obesity among professional drivers: the high risk professional driver study. Am J Ind Med 2015;58:212-9.

37. Leinonen T, Pietiläinen O, Laaksonen M, et al. Occupational social class and disability retirement among municipal employees--the contribution of health behaviors and working conditions. Scand $J$ Work Environ Health 2011;37:464-72.

38. Knudsen AK, Øverland S, Hotopf M, et al. Lost working years due to mental disorders: an analysis of the Norwegian disability pension registry. PLoS One 2012;7:e42567.

39. Järvholm B, Stattin M, Robroek SJ, et al. Heavy work and disability pension - a long term follow-up of Swedish construction workers. Scand J Work Environ Health 2014;40:335-42.

40. Polvinen A, Laaksonen M, Gould R, et al. The contribution of major diagnostic causes to socioeconomic differences in disability retirement. Scand J Work Environ Health 2014;40:353-60. 